Article Type: Clinical Article

CLINICAL ARTICLE

\title{
A survey of opinion and practice regarding prenatal diagnosis of vasa previa among obstetricians from Australia and New Zealand
}

Nasrin Javid ${ }^{*}$, Jonathan A. Hyett ${ }^{2}$, Susan P. Walker ${ }^{3}$, Elizabeth A. Sullivan ${ }^{1}$, Caroline S. E. Homer ${ }^{1}$

${ }^{1}$ Faculty of Health, University of Technology Sydney, Sydney, Australia

${ }^{2}$ Department of Obstetrics and Gynaecology, Royal Prince Alfred Hospital, Faculty of Medicine, University of Sydney, Sydney, Australia

${ }^{3}$ Department of Obstetrics and Gynaecology, Mercy Hospital for Women, Faculty of Medicine, University of Melbourne, Melbourne, Australia

\section{*Correspondence}

Nasrin Javid, Faculty of Health, University of Technology Sydney, PO Box 123, Broadway, New South Wales, 2007, Australia

E-mail: Nasrin.javid@uts.edu.au

Keywords: Content validation; Placenta previa; Prenatal diagnosis; Screen; Survey; Ultrasound imaging; Vasa previa; Velamentous cord insertion

Synopsis: Despite a lack of consensus on the definition of vasa previa, most obstetricians in Australia and New Zealand support targeted screening for vasa previa.

\section{ABSTRACT}

Objectives: To define current obstetric opinion and clinical practice regarding the prenatal diagnosis of vasa previa in Australia and New Zealand.

This is the author manuscript accepted for publication and has undergone full peer review but has not been through the copyediting, typesetting, pagination and proofreading process, which may lead to differences between this version and the Version of Record. Please cite this article as doi: $10.1002 / \mathrm{IJGO} 0.12747$

This article is protected by copyright. All rights reserved 
Methods: A population-based cross-sectional survey of Fellows of the Royal Australian and New Zealand College of Obstetricians and Gynaecologists was conducted from April to May, 2016. Descriptive analysis was used to define factors influencing opinion and practice regarding definition of vasa previa, attributable risk factors, and the value of screening.

Results: Overall, 453 respondents were included in the study. Two-thirds (304/453; $67.1 \%$ ) defined vasa previa as exposed fetal vessel(s) running over or within $2 \mathrm{~cm}$ of the internal os. A higher proportion of ultrasound specialists $(30 / 65 ; 46.2 \%)$ preferred a broader definition as compared with generalists (115/388; 29.6\%; $P<0.001)$. Overall, Fellows were supportive (342/430; 79.5\%) of both reporting ultrasoundbased risk factors at the 20-week anomaly scan and targeted screening (298/430; $69.3 \%)$. Only $77 / 453(17.0 \%)$ respondents recognized all five "known" risk factors for vasa previa.

Conclusions: There was a lack of consensus regarding the definition and diagnosis process for vasa previa. There was also a knowledge gap in risk factors for vasa previa that would inform a targeted screening policy. Nevertheless, support for targeted screening was strong from obstetricians who responded.

\section{INTRODUCTION}

Prenatal diagnosis of vasa previa (VP) is an important determinant of perinatal outcome [1-4]. Failure to diagnose VP is associated with high rates of perinatal mortality $(40 \%-60 \%)[2,5]$ and morbidity [1-6]. Poor outcomes are related to unanticipated rupture of fetal vessels that run unprotected across the supracervical site through the chorionic membrane, rather than being supported by the placenta or the umbilical cord [6].

Vasa previa is most effectively diagnosed by transvaginal ultrasound using color Doppler [7], which has been shown to have sensitivity, specificity, and positive and negative predictive values of $100 \%, 99.8 \%, 83 \%$, and $100 \%$ respectively. Nevertheless, there remains controversy over the use of universal rather than targeted screening [8].

The prevalence of VP has been reported as 1 per $1600-5000$ deliveries [2,8]. This low prevalence means the positive predictive value of universal screening is likely to This article is protected by copyright. All rights reserved 
be poor, and there is the potential to do harm through unnecessary interventions such as corticosteroid administration, hospital admission, and iatrogenic preterm cesarean delivery. Conversely, $17 \%$ of women with VP have no established risk factors such as velamentous cord insertion, low-lying placenta, succenturiate or bilobed placenta, in vitro fertilization (IVF), or multiple gestation. These women would therefore not be identified through targeted screening [9].

Universal VP screening is not recommended nationally or internationally [10-13], but targeted screening is currently recommended by the Society of Obstetricians and Gynaecologists of Canada [13] and the Royal Australian and New Zealand College of Obstetricians and Gynaecologists (RANZCOG) [10]. The aim of the present study was to determine opinion and clinical practice regarding the prenatal diagnosis of VP in Australia and New Zealand (ANZ) and explore factors that may influence the views and/or practice of clinicians.

\section{MATERIALS AND METHODS}

The present population-based cross-sectional survey was carried out among RANZCOG Fellows between April and May, 2016. The study was approved by the Human Research Ethics Committee of the University of Technology Sydney, Sydney, Australia. Participants were advised that completion and online submission of the survey implied consent.

The anonymous self-administered online questionnaire was emailed to 2026 RANZCOG Fellows who currently practice obstetrics/obstetric ultrasound, together with an invitation to participate in the study. A "reminder" email was sent 2 weeks later.

The survey was designed after conducting a comprehensive literature review $[5,14$ 20], and informed by a previous international survey [21] and qualitative work [22] on VP. Content and face validation [23] were performed through two rounds of assessment by five Australian and five international experts who independently reviewed the survey for content, clarity, relativeness, and representativeness (Figure 1). The survey (Survey Gizmo, Version 4, Colorado, USA) included 26 questions (Supplementary File S1).

This article is protected by copyright. All rights reserved 
Respondents were grouped into three groups: those do not perform ultrasound; those who perform office ultrasound or have extensive experience in performing ultrasound but no formal certificate; and those who are ultrasound specialists (i.e., possess a Diploma of Diagnostic Ultrasound, Certification in Obstetrical and Gynecological Ultrasound, or Certification in Maternal Fetal Medicine).

Universal screening was defined as screening of all women during their anomaly scan at 18-20 gestational weeks; targeted screening was defined as screening of only those women with known VP risk factors. The respondents' knowledge of five known VP risk factors [9] was assessed and reported as a score of $0-5$. The scores were treated as continuous data and a "mean awareness score" was calculated. The respondents' response to four different statements regarding VP diagnosis was assessed by using four individual seven-point Likert scale questions ranging from "strongly disagree" to "strongly agree."

Data were analyzed by using SPSS version 23 (IBM, Armonk, NY, USA). Categoric data were analyzed by using Pearson $\square$ test. Continuous data were analyzed by using analysis of variance. A $P$ value of less than 0.05 was considered statistically significant.

\section{RESULTS}

Of the 559/2026 (27.9\%) Fellows who responded to the survey invitation, 71 did not meet the inclusion criteria (Figure 2). Among the 488 respondents who were eligible, 453 completed the survey. Most Fellows (384/453; 84.8\%) performed some obstetric ultrasound (Table 1). There were 65 ultrasound specialists and 69 obstetricians who did not perform obstetric ultrasound. The median age was 50 years (SD, 10.4 years; range, $31-82$ years). The median duration of practice was 14 years (range, $<1$ to 53 years).

There was little consensus over the definition of VP (Figure 3). One-third (159/453; $35.1 \%)$ preferred the definition "exposed fetal vessels running directly over the internal os", whereas two-thirds $(304 / 453 ; 67.1 \%)$ chose a definition describing a vessel running over or within $2 \mathrm{~cm}$ of the internal os. A higher proportion of imaging This article is protected by copyright. All rights reserved 
specialists preferred the broader definition (30/65; 46.2\%) relative to those who used imaging only as part of their own prenatal care $(107 / 319 ; 33.5 \%)$ or those who did not perform their own imaging (8/69; 11.6\%; $P<0.001)$. Overall, 83/453 (18.3\%) respondents reported that any vessel running through the membrane in the lower segment should be included; however, the proportion of respondents preferring this definition was higher among those who did not perform ultrasound (15/69; $21.7 \%)$ than among ultrasound specialists $(7 / 65 ; 10.8 \% ; P=0.001)$.

Opinion varied over the gestational age at which a formal VP diagnosis could be made (Figure 4). One-quarter (111/453; 24.5\%) reported that a diagnosis could be made at the 20 -week ultrasound, but almost half $(211 / 453 ; 46.6 \%)$ reported that a diagnosis could be made only during the third trimester. There was a range of views about whether a third trimester diagnosis could be made as early as 28 or as late as 36 weeks. Opinion varied by the level of ultrasound performed by the respondents: $27 / 65(41.5 \%)$ ultrasound specialists reported that a diagnosis could be made at 18 20 weeks, but only $8 / 69$ (11.6\%) respondents who did not perform ultrasound held this view $(P=0.001)$.

Respondents recognized several risk factors for VP. There was a high level of consensus recognizing the association with velamentous cord insertion (394/453; $87.0 \%$ ), succenturiate/bi-lobed placenta (393/453; 86.8\%), or placenta previa/lowlying placenta at 18-20 weeks (350/453; 77.3\%) as risk factors for VP. Other risk factors were less frequently recognized including multiple pregnancy (170/453; $37.5 \%)$ and IVF (140/453; 30.9\%). Only 77 (17.0\%) respondents identified all five of these risk factors (mean awareness score [M], 3.19; range, 0-5; 95\% confidence interval [Cl], 3.08-3.31). There was a significant difference in the awareness of risk factors between ultrasound specialists (M, 3.55; 95\% Cl, 3.20-3.91) and those who did not perform ultrasound (M, 2.90; 95\% Cl, 2.55-3.25; $P=0.010)$.

Several participants mentioned factors that are not typically associated with VP, including previous cesarean delivery (96/453; $21.2 \%)$, placenta accreta (78/453; $17.2 \%)$, previous uterine surgery (56/453; 12.4\%), cord presentation (50/453; $11.0 \%)$, advanced maternal age $(30 / 453 ; 6.6 \%)$, and breech presentation (22/453; $4.9 \%)$.

This article is protected by copyright. All rights reserved 
Most (340; 78.5\%) of the 433 respondents indicated that a bi-lobed/succenturiate lobed placenta was routinely reported at the 20-week scan, but only 201 (46.4\%) indicated that placental-cord insertion site was routinely reported. Some respondents were unsure whether a bi-lobed/succenturiate lobed placenta $(n=28 ; 6.5 \%)$ or cord insertion site $(n=31 ; 7.2 \%)$ was routinely reported at the 20 -week scan in their facility. Nevertheless, $342(79.5 \%)$ of the 430 respondents thought that the cord insertion site should be reported at the 20-week scan (Table 2). More clinicians based in rural $(31 / 34 ; 91.2 \%)$ and regional $(97 / 118 ; 82.2 \%)$ communities responded that placentalcord insertion type should be reported at the 18-20 weeks scan relative to clinicians in metropolitan areas (214/278; 77.0\%), although the difference was not significant $(P=0.180)$.

Two-thirds (298/430; 69.3\%) of the respondents agreed with targeted VP screening (Table 2). Most (350/429; 81.6\%) reported that, in circumstances where the placenta was low-lying at the 20-week scan, VP should be ruled out in the third trimester. A higher proportion of ultrasound specialists supported targeted screening (47/63; $74.6 \%)$ relative to general obstetricians $(251 / 367 ; 68.4 \%)$, but a lower proportion of specialists advocated screening in the third trimester for women who had a low-lying placenta in the second trimester (48/63 [76.2\%] vs 302/366 [82.5\%]). However, neither of these differences was statistically significant $(P=0.400$ and $P=0.246$, respectively). Senior obstetricians ( $\geq 20$ years consultant experience) were less likely to support targeted screening $(90 / 154 ; 58.4 \%)$ than those with less experience (208/276; 75.4\%; $P<0.001$ ), as were those who did not perform ultrasound (37/65; $56.9 \%)$ when compared to those who performed ultrasound $(261 / 365 ; 71.5 \%$; $P=0.036)$.

Sixty-two of the 65 ultrasound specialists reported about their practice on universal or targeted screening for VP. Most $(49 ; 79.0 \%)$ would screen either universally (28; $45.2 \%)$ or in a targeted manner $(21 ; 33.9 \%)$. For universal screening, they reported using color Doppler transabdominally $(11 ; 17.7 \%)$, color Doppler transvaginally ( 9 ; $14.5 \%)$, or color Doppler transabdominally for women with no risk factors but color Doppler transvaginally for women with risk factors $(8 ; 12.9 \%)$. For targeted screening, they performed transvaginal color Doppler ultrasound $(11 ; 17.7 \%)$, This article is protected by copyright. All rights reserved 
applied color Doppler transabdominally $(9 ; 14.5 \%)$, or performed transvaginal ultrasound $(1 ; 1.6 \%)$. During the third trimester, $81.7 \%$ (49/60) reported that they would exclude VP in women who previously had a low-lying placenta by performing transvaginal color Doppler ultrasound $(37 ; 61.7 \%)$, applying color Doppler transabdominally $(11 ; 18.3 \%)$, or performing transvaginal ultrasound $(1 ; 1.7 \%)$.

\section{DISCUSSION}

To our knowledge, the present survey is the first to address VP screening and diagnosis practice among obstetricians in ANZ. The study showed little consensus over (1) the precise definition of VP, (2) when a diagnosis can be achieved, and (3) who merits targeted screening. Only two-thirds of respondents defined VP as an exposed fetal vessel running over or within $2 \mathrm{~cm}$ of the internal os. A significantly higher proportion of ultrasound specialists, as compared with generalists, chose a 2$\mathrm{cm}$ cutoff as opposed to directly over the internal os. Overall, the level of awareness regarding VP diagnosis was higher among ultrasound specialists. Younger obstetricians had greater confidence in ultrasound diagnosis as compared with those who had been practicing for more than 20 years.

The lack of consensus about the definition of VP is not surprising given a lack of clarity in the literature and among international experts regarding VP. There is a wide range of definitions for VP, including exposed fetal blood vessels over the internal os [14] or cervix [16,17]; within $1 \mathrm{~cm} \mathrm{[18],} 2 \mathrm{~cm}$ [15], $3 \mathrm{~cm} \mathrm{[6],} \mathrm{or} 4 \mathrm{~cm}$ of the internal os [8]; close to the internal os [19]; within the lower uterine segment in front of the fetal presenting part [20]; or arterial vessels close to the internal os [12]. There is currently no expert international consensus or data defining the level of risk of rupture of VP according to these varied definitions to inform the optimal cutoff. The positive predictive value will always be low when screening for a low-prevalence condition; however, the implications of a false-positive diagnosis of VP would be significant for the affected families and health system. Increasing the distance from the internal os for diagnosis would increase sensitivity very slightly, but might also increase the false-positive rate (with attendant morbidity). Given the lack of robust data, there is a need for international consensus on the definition of VP. 
Current guidelines in Australia and Canada recommend targeted screening using transvaginal color Doppler ultrasound $[10,13]$. The present study found that twothirds of obstetricians agree with targeted screening, and $79 \%$ of ultrasound specialists have adopted screening for VP either universally or in a targeted manner. However, only $45 \%$ of ultrasound specialists use the recommended method for screening, and 32\% apply color Doppler during transabdominal scanning. These findings suggest a need for education to standardize targeted screening and ensure that practice is aligned with current guidelines. Nevertheless, the study demonstrated a significant change in practice among the profession over the years. In 2006, a UK survey of 128 obstetricians recommended against targeted screening [21]. In that study, 5 (4\%) obstetricians reported that placental-cord insertion type was routinely reported at the 20-week scan, and only 42 (33\%) indicated that their hospital trust offered transvaginal color Doppler ultrasound for identification of VP, although practice may have changed in the 10 years since that study. In the present survey, most (313/430; 73\%) obstetricians supported universal screening for placental-cord insertion, and almost half $(201 / 433 ; 46 \%)$ indicated that this was routinely reported in their practice. These findings suggest that there may be a move to accept targeted screening for VP.

Implementation of targeted screening requires awareness of the risk factors. Despite the apparent improvement in recognition of risk factors for VP $(1.5 \%$ in the UK survey [21] vs 17\% in the present survey), there seem to be knowledge gaps: IVF, which is associated with a 1 in 208 incidence of VP [16], was recognized as a risk factor by only one-third of respondents. Introducing a policy of targeted screening will fail unless risk factors are accurately identified. Although universal screening will improve sensitivity, the decrease in positive predictive value will have a significant impact through unnecessary intervention and healthcare costs.

Screening, whether targeted or universal, is feasible at 18-20 weeks when a routine scan is offered to all pregnant women. As the potential outcome of ruptured VP includes perinatal death, any screening test needs to be highly sensitive. Falsenegative cases have been reported, but mainly in retrospective case series where VP was assessed in the third trimester [14], or the focus was on the use of transvaginal ultrasound to predict cervical length [16]. In contrast, prospective series This article is protected by copyright. All rights reserved 
have shown very high sensitivity; for example. Rebarber et al. [15] reported "no known" false negatives in a series of 27573 prospective transvaginal color Doppler screening scans [15].

The concept of VP screening remains controversial. Screening is not recommended in the United Kingdom [11], whereas obstetric colleges in Australia and Canada recommend targeted screening $[10,13]$. A previous economic analysis suggested that only targeted screening would be cost-effective [24]. However, it did not take into account a recent change in practice, whereby many sonographers and obstetricians now include transvaginal ultrasound assessment of the cervix in the routine second trimester scan to assess risk of preterm delivery [25]. Vasa previa might be reliably ruled out during this examination without an apparent increase in cost. Non-economic costs related to the impact of perinatal mortality and morbidity [4], and women's views regarding VP screening also need to be considered. A qualitative study reported that women felt grateful for prenatal diagnosis of VP, and those who did not have prenatal diagnosis queried the health system for not providing screening [22].

Screening to detect exposed fetal vessels in the lower uterine segment, reporting the distance of the vessels from the internal os, and following up women postpartum to investigate perinatal outcomes might ultimately make the definition of VP clearer. Large prospective multi-center studies are needed to link the ultrasound findings of 20-week anomaly scans with perinatal outcomes to accurately assess the performance of screening strategies and the effect of intervention on maternal, perinatal, and cost outcomes.

The study has some limitations. First, the results cannot be generalized to all obstetricians because the participants were from ANZ. Second, not all obstetricians in ANZ completed the survey, and the number of RANZCOG Fellows who currently practice obstetrics and/or obstetric ultrasound in ANZ is unknown.

The strengths of the survey include its preparation: the survey content was considered to be valid by an international expert panel. Another strength is the unprecedented sample size for a survey on this topic. Notably, $40 \%$ of the Fellows This article is protected by copyright. All rights reserved 
who had CMFM or COGU accreditation responded. The lower response rate of other Fellows might reflect many factors, such as being less familiar with VP, having less confidence about the role of prenatal diagnosis (a topic subject to debate and controversy), or feeling that participation might cause distress (e.g., if they had previously been involved in an adverse outcome).

In conclusion, the study has demonstrated that support for targeted screening is high among a group of obstetricians in ANZ. However, there is a lack of consensus regarding the definition and process to diagnose VP. There is a knowledge gap in risk factors for VP that would inform a targeted screening policy. Introducing targeted educational activities and screening tools might enhance clinical practice on the diagnosis, and ultimately improve perinatal outcomes for women with VP.

\section{Author contributions}

$\mathrm{NJ}, \mathrm{JAH}, \mathrm{SPW}, \mathrm{EAS}$, and CSE contributed to study design and conduct. NJ and JAH analyzed the data. $\mathrm{NJ}$ drafted the manuscript. All authors contributed to data interpretation and critical revision of the manuscript, and approved the final version for publication.

\section{Acknowledgments}

The study was supported by an Australian Government Research Training Program Scholarship.

\section{Conflicts of interest}

The authors have no conflicts of interest.

\section{References}

1. Melcer $Y$, Jauniaux E, Maymon S, et al. Impact of Targeted Scanning Protocols on Perinatal Outcomes in Pregnancies at Risk of Placenta Accreta Spectrum or Vasa Previa. Am J Obstet Gynecol. 2018; 218:443.e1-8.

2. Sullivan EA, Javid N, Duncombe G, et al. Vasa Previa Diagnosis, Clinical Practice, and Outcomes in Australia. Obstet Gynecol. 2017; 130:591-598.

3. Swank ML, Garite TJ, Maurel K, et al. Vasa previa: diagnosis and management. Am J Obstet Gynecol. 2016; 215:223.e1-6.

This article is protected by copyright. All rights reserved 
4. Javid N, Hyett JA, Homer CSE: The experience of vasa praevia for Australian midwives: A qualitative study. Women Birth 2018.

https://doi.org/10.1016/j.wombi.2018.06.020.

5. Oyelese Y, Catanzarite V, Prefumo F, et al. Vasa previa: the impact of prenatal diagnosis on outcomes. Obstet Gynecol. 2004; 103:937-942.

6. Bronsteen $\mathrm{R}$, Whitten A, Balasubramanian M, et al. Vasa previa: clinical presentations, outcomes, and implications for management. Obstet Gynecol. 2013; 122:352-357.

7. Ruiter L, Kok N, Limpens J, et al. Systematic review of accuracy of ultrasound in the diagnosis of vasa previa. Ultrasound Obstet Gynecol. 2015; 45:516-522.

8. Kulkarni A, Powel J, Aziz M, et al. Vasa Previa: Prenatal Diagnosis and Outcomes: Thirty-five Cases From a Single Maternal-Fetal Medicine Practice. J Ultrasound Med. 2018; 37:1017-1024.

9. Ruiter L, Kok N, Limpens J, et al. Incidence of and risk indicators for vasa praevia: a systematic review. BJOG. 2016; 123:1278-1287.

10. Royal Australian and New Zealand College of Obstetricians and Gynaecologists. Vasa praevia (C-Obs 47).

https://www.ranzcog.edu.au/RANZCOG SITE/media/RANZCOGMEDIA/Women's\%20Health/Statement\%20and\%20guidelines/ClinicalObstetrics/Vasa-praevia-(C-Obs-47)-Review-July-2016.pdf?ext=.pdf. Published 2016. Accessed September 2016.

11. Jauniaux ERM, Alfirevic Z, Bhide AG, et al. Vasa praevia: diagnosis and management. Green-top Guideline No. 27b. BJOG. 2018. https://doi.org/10.1111/1471-0528.15307.

12. The Society for Maternal-Fetal Medicine Publications Committee, Sinkey RG, Odibo AO, Dashe JS. \#37: Diagnosis and management of vasa previa. Am J Obstet Gynecol 2015;213:615-619.

13. Gagnon R, Morin L, Bly S, et al. SOGC clinical practice guideline: guidelines for the management of vasa previa. Int J Gynecol Obstet. 2010; 108:85-89.

14. Lee W, Lee VL, Kirk JS, Sloan CT, Smith RS, Comstock CH. Vasa previa: prenatal diagnosis, natural evolution, and clinical outcome. Obstet Gynecol. 2000; 95:572-576. 
15. Rebarber A, Dolin C, Fox NS, Klauser CK, Saltzman DH, Roman AS. Natural history of vasa previa across gestation using a screening protocol. J Ultrasound Med. 2014; 33:141-147.

16. Baulies S, Maiz N, Munoz A, Torrents M, Echevarria M, Serra B. Prenatal ultrasound diagnosis of vasa praevia and analysis of risk factors. Prenat Diagn 2007; 27:595-599.

17. Catanzarite V, Maida C, Thomas W, Mendoza A, Stanco L, Piacquadio KM. Prenatal sonographic diagnosis of vasa previa: ultrasound findings and obstetric outcome in ten cases. Ultrasound Obstet Gynecol 2001; 18:109-115.

18. Golic M, Hinkson L, Bamberg C, et al. Vasa praevia: risk-adapted modification of the conventional management-a retrospective study. Ultraschall Med. 2013; 34:368-376.

19. Hasegawa J, Farina A, Nakamura M, et al. Analysis of the ultrasonographic findings predictive of vasa previa. Prenat Diagn. 2010; 30:1121-1125.

20. Nomiyama M, Toyota $\mathrm{Y}$, Kawano H. Antenatal diagnosis of velamentous umbilical cord insertion and vasa previa with color Doppler imaging. Ultrasound Obstet Gynecol. 1998; 12:426-429.

21. Ioannou C, Wayne C. Diagnosis and management of vasa previa: a questionnaire survey. Ultrasound Obstet Gynecol. 2010; 35:205-209.

22. Javid N, Sullivan EA, Halliday LE, Duncombe G, Homer CS. "Wrapping myself in cotton wool": Australian women's experience of being diagnosed with vasa praevia. BMC Pregnancy Childbirth. 2014; 14:318.

23. Polit DF, Beck CT. The content validity index: are you sure you know what's being reported? Critique and recommendations. Res Nurs Health. 2006; 29:489-497. 24. Cipriano L, Barth W, Zaric G. The cost-effectiveness of targeted or universal screening for vasa praevia at 18-20 weeks of gestation in Ontario. BJOG. 2010; 117:1108-1118.

25. Marren AJ, Mogra R, Pedersen LH, Walter M, Ogle RF, Hyett JA. Ultrasound assessment of cervical length at 18-21 weeks' gestation in an Australian obstetric population: Comparison of transabdominal and transvaginal approaches. Aust N Z J Obstet. 2014; 54:250-255. 
Figure 1 Process of developing the vasa previa survey. Abbreviations: RANZCOG, Royal Australian and New Zealand College of Obstetricians and Gynaecologists.

Figure 2 Flowchart showing participants in the survey. The survey was addressed to Fellows who currently practice obstetrics and/or obstetric ultrasound, the exact number of which is unknown. The response rate was expected to be higher than reported. The invited RANZCOG Fellows included those who have a sub-specialty Certification in Obstetrical and Gynaecological Ultrasound $(n=41)$ and Maternal Fetal Medicine $(\mathrm{n}=55)$. Abbreviations: RANZCOG, Royal Australian and New Zealand College of Obstetricians and Gynaecologists.

Figure 3 Views on the definition of vasa previa within each group of respondents. Abbreviations: IO, internal os; US, ultrasound. *Other includes those who preferred not to answer or chose other.

Figure 4 Views on gestational age for accurate diagnosis of vasa previa within each group of respondents. Abbreviations: US, ultrasound. *Other includes respondents who preferred not to answer or chose "other."

\section{Supporting materials legends}

File S1 Participant questionnaire.

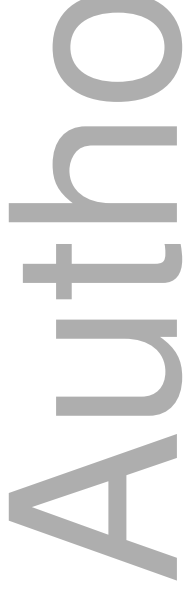


Table 1 Characteristics of obstetricians in Australia and New Zealand $(n=453){ }^{a}$

\begin{tabular}{|c|c|c|c|c|}
\hline \multirow{2}{*}{ Characteristic } & \multirow[t]{2}{*}{ Total $(n=453)$} & \multirow{2}{*}{$\begin{array}{l}\text { Do not perform } \\
\text { obstetric US } \\
(n=69)\end{array}$} & \multicolumn{2}{|c|}{ Perform obstetric US $(n=384)$} \\
\hline & & & $\begin{array}{l}\text { Perform office } \\
\text { US }(n=319)^{b}\end{array}$ & $\begin{array}{l}\text { US } \\
\text { specialist } \\
(n=65)^{c}\end{array}$ \\
\hline \multicolumn{5}{|l|}{ Country of practice } \\
\hline Australia & $388(85.7)$ & $51(73.9)$ & $281(88.1)$ & $56(86.2)$ \\
\hline New Zealand & $65(14.3)$ & $18(26.1)$ & $38(11.9)$ & $9(13.8)$ \\
\hline \multicolumn{5}{|l|}{ Age group, $y^{d}$} \\
\hline$<40$ & $74(16.5)$ & $9(13.0)$ & $57(18.0)$ & $8(12.7)$ \\
\hline $40-49$ & $134(29.8)$ & $11(15.9)$ & $105(33.1)$ & $18(28.6)$ \\
\hline $50-59$ & $142(31.6)$ & $23(33.3)$ & $95(30.0)$ & $24(38.1)$ \\
\hline$\geq 60$ & $99(22.0)$ & $26(37.7)$ & $60(18.9)$ & $13(20.6)$ \\
\hline \multicolumn{5}{|c|}{$\begin{array}{l}\text { Duration of practice as } \\
\text { consultant, } y\end{array}$} \\
\hline$<5$ & $99(21.9)$ & $12(17.4)$ & $73(22.9)$ & $14(21.5)$ \\
\hline $5-9$ & $67(14.8)$ & $8(11.6)$ & $54(16.9)$ & $5(7.7)$ \\
\hline $10-19$ & $120(26.5)$ & $6(8.7)$ & $101(31.7)$ & $13(20.0)$ \\
\hline $20-29$ & $96(21.2)$ & $18(26.1)$ & $53(16.6)$ & $25(38.5)$ \\
\hline$\geq 30$ & $71(15.7)$ & $25(36.2)$ & $38(11.9)$ & $8(12.3)$ \\
\hline Location of practic & & & & \\
\hline
\end{tabular}

This article is protected by copyright. All rights reserved 


\begin{tabular}{|l|l|l|l|l|}
\hline Metropolitan & $293(64.7)$ & $40(58.0)$ & $201(63.0)$ & $52(80.0)$ \\
\hline Regional & $125(27.6)$ & $24(34.8)$ & $90(28.2)$ & $11(16.9)$ \\
\hline Rural & $35(7.7)$ & $5(7.2)$ & $28(8.8)$ & $2(3.1)$ \\
\hline Type of practice & & & & \\
\hline Public & $181(40.0)$ & $36(52.2)$ & $125(39.2)$ & $20(30.8)$ \\
\hline Private & $88(19.4)$ & $12(17.4)$ & $67(21.0)$ & $9(13.8)$ \\
\hline Both public and private & $184(40.6)$ & $21(30.4)$ & $127(39.8)$ & $36(55.4)$ \\
\hline
\end{tabular}

Abbreviation: US, ultrasound.

${ }^{a}$ Values are given as number (percentage).

${ }^{b}$ Includes obstetricians who perform ultrasound in their office $(n=272)$, or have extensive experience in ultrasound but no formal certificate $(n=47)$.

'US specialists are obstetricians who have a Diploma of Diagnostic Ultrasound $(n=28)$, Certification in Obstetrical and Gynaecological Ultrasound ( $n=15)$, or Certification in Maternal Fetal Medicine $(n=22)$.

${ }^{d}$ Missing data due to error in data entry $(4 ; 0.9 \%)$.

Table 2 Views of obstetricians towards targeted screening for vasa previa $(n=453)^{a}$

\begin{tabular}{|l|l|l|l|l|l|l|}
\hline $\begin{array}{l}\text { How much you agree or } \\
\text { disagree with the statements }\end{array}$ & $\begin{array}{l}\text { Strongly } \\
\text { disagree }\end{array}$ & Disagree & $\begin{array}{l}\text { Somewhat } \\
\text { disagree }\end{array}$ & $\begin{array}{l}\text { Neither } \\
\text { agree nor } \\
\text { disagree }\end{array}$ & $\begin{array}{l}\text { Somewhat } \\
\text { agree }\end{array}$ & $\begin{array}{l}\text { Agree } \\
\text { agree }\end{array}$ \\
\hline
\end{tabular}

This article is protected by copyright. All rights reserved 


\begin{tabular}{|c|c|c|c|c|c|c|c|}
\hline $\begin{array}{l}\text { Placental cord insertion type } \\
\text { should be identified at 18-20- } \\
\text { wk morphology scan }^{\text {b }}\end{array}$ & $15(3.5)$ & $22(5.1)$ & $25(5.8)$ & 55 (12.8) & $72(16.7)$ & 159 (37.0) & $82(19.1)$ \\
\hline $\begin{array}{l}\text { Placental cord insertion type } \\
\text { should be reported at 18-20- } \\
\text { wk morphology scan when it is } \\
\text { technically possible }\end{array}$ & $16(3.7)$ & $18(4.2)$ & $15(3.5)$ & $39(9.1)$ & $68(15.8)$ & 186 (43.3) & $88(20.5)$ \\
\hline $\begin{array}{l}\text { Vasa previa should be } \\
\text { excluded among women with } \\
\text { risk factors for vasa previa at } \\
\text { the 18-20-wk morphology } \\
\text { scan }^{\text {b }}\end{array}$ & 14 (3.3) & $25(5.8)$ & $28(6.5)$ & 65 (15.1) & 76 (17.7) & $146(34.0)$ & $76(17.7)$ \\
\hline $\begin{array}{l}\text { At the 32-34-wk scan, vasa } \\
\text { previa should be excluded } \\
\text { among women who previously } \\
\text { had placenta previa or low- } \\
\text { lying placenta in the second } \\
\text { trimester }^{c}\end{array}$ & $7(1.6)$ & $17(4.0)$ & $12(2.8)$ & $43(10.0)$ & 45 (10.5) & $180(42.0)$ & $125(29.1)$ \\
\hline
\end{tabular}

${ }^{a}$ Values are given as number (percentage).

${ }^{b}$ Data were missing for $23(5.1 \%)$ respondents.

${ }^{\mathrm{c}}$ Data were missing for 24 (5.3\%) respondents.

This article is protected by copyright. All rights reserved 


\section{Development Stage}

1) Comprehensive literature review

2) Identification of four content domains (definition, risk factors, diagnosis, management)

3) Construct questions under each domain

4) Build the survey online (Survey Gizmo)

5) Review, and modify

\section{Pilot Test with Australian Experts}

6) Identify Australian Expert review team (three obstetricians, one senior obstetric sonographer, and one consumer group representative).

7) Email the online survey with study aims and objectives to the experts, asking them to review the content of the survey and provide written comments.

8) Conduct interview face-to face or by phone to discuss the comments.

9) Review comments and modify survey questions.

\section{Judgement Stage with International Experts}

10) Identify International Expert review team (five senior obstetricians from Canada, Denmark, Japan, the United Kingdom, and the United States).

11) Develop content validation survey online (Survey Gizmo), which used Likert 4-point scale to measure experts' opinion to the study questions.

12) Email the content validation survey to the experts, together with the study aims and objectives. They were asked to review the survey questions for clarity, relativeness, and representativeness; and indicate whether each question is: 1) not relevant, 2) somewhat relevant, 3) quite relevant, or 4) highly relevant. Experts were asked to identify any question that was poorly worded and write their preferred wording in the text box provided. They were also asked to write any extra question(s) that they believed had to be added to the survey to ensure representative content is assessed by the instrument.

13) Calculate content validity index. Of 19 questions, 15 received an item content validation of 1.0 and remained unchanged. Four received an item content validation of $0.8 ; 2$ were revised and 2 removed. Four additional questions were added as recommended.

14) The survey was reviewed by the RANZCOG Continuing Professional Development

committee who requested one additional question.

15) Incorporate changes to finalise the survey. 


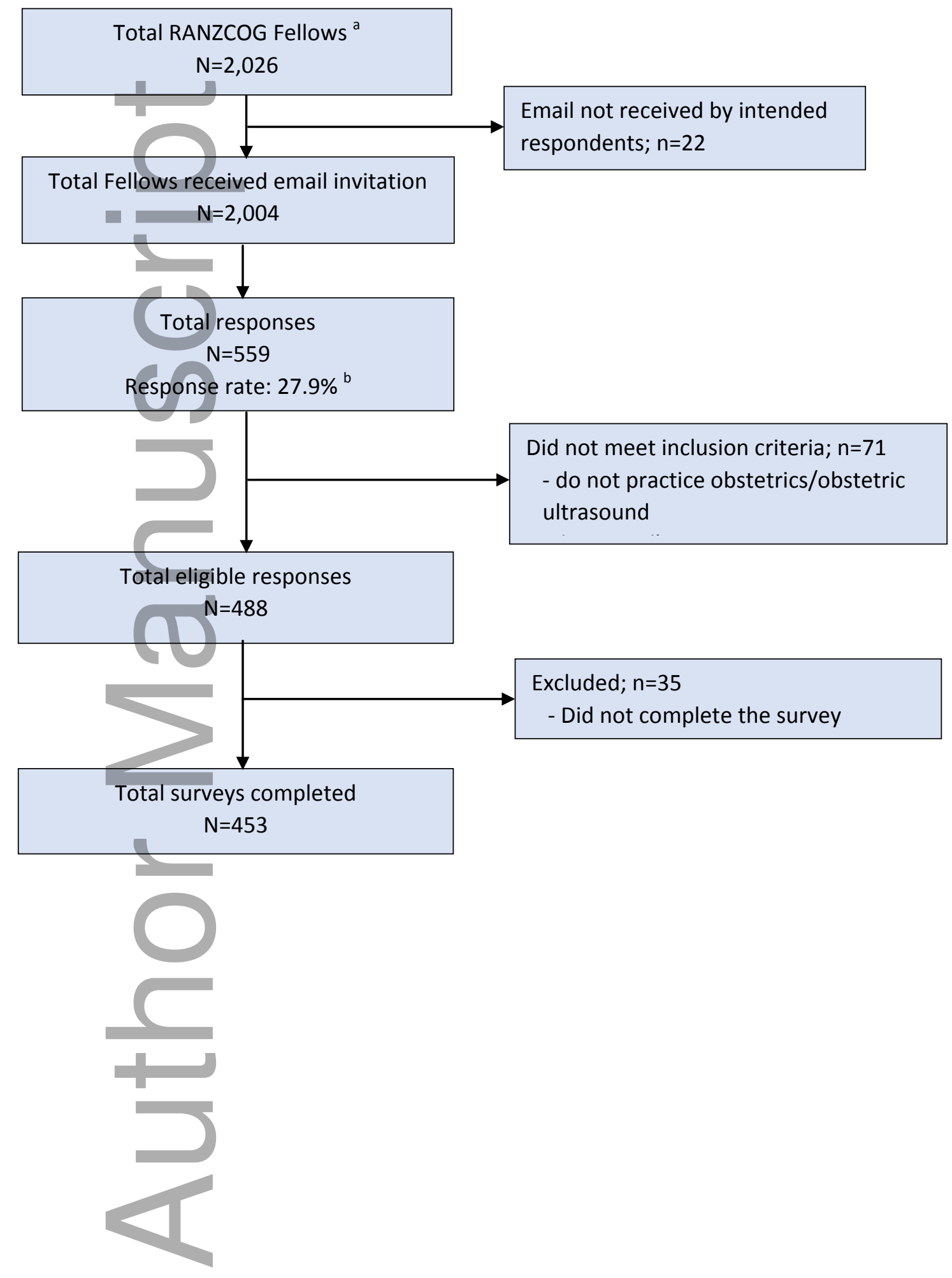

This article is protected by copyright. All rights reserved 


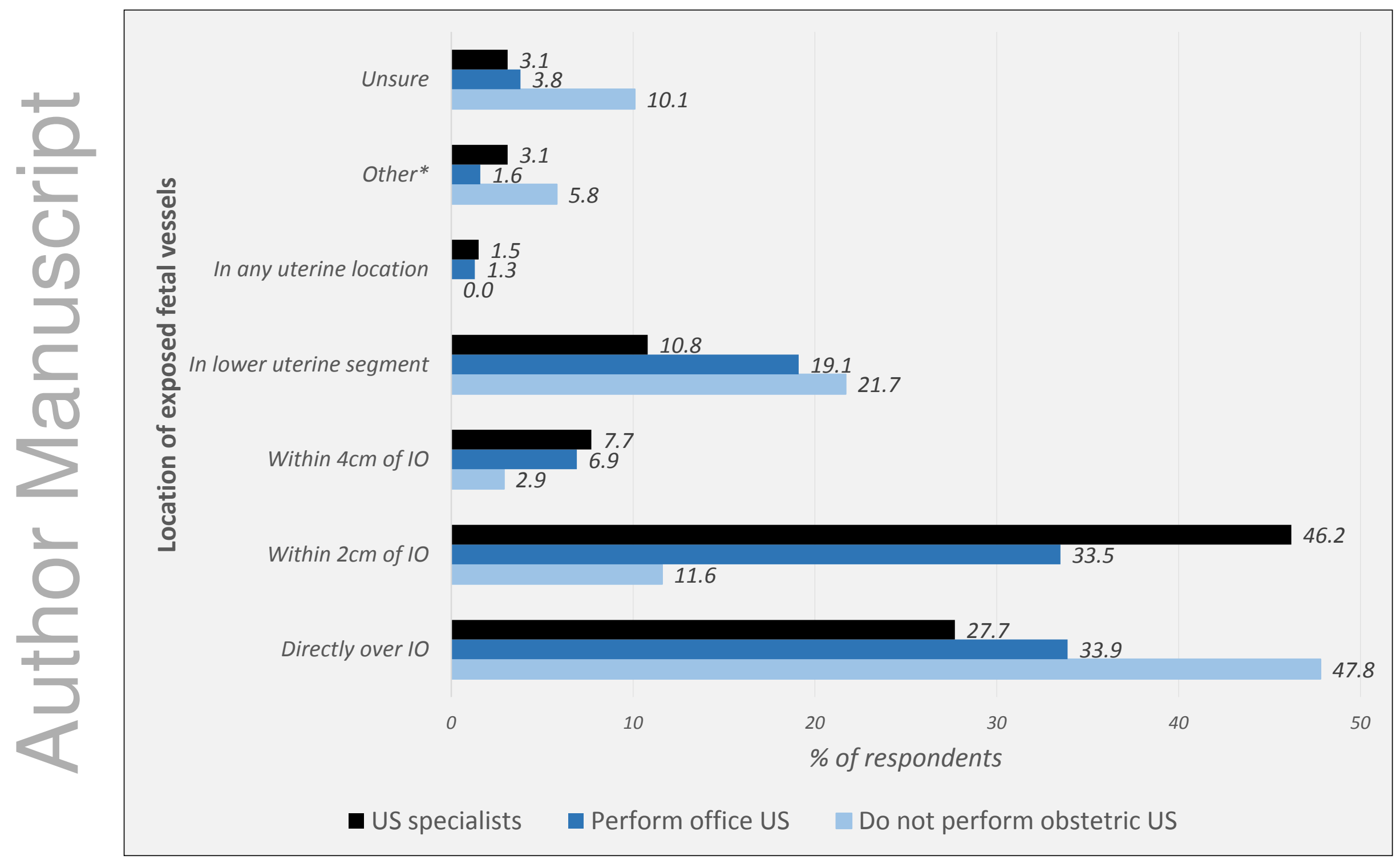

This article is protected by copyright. All rights reserved 


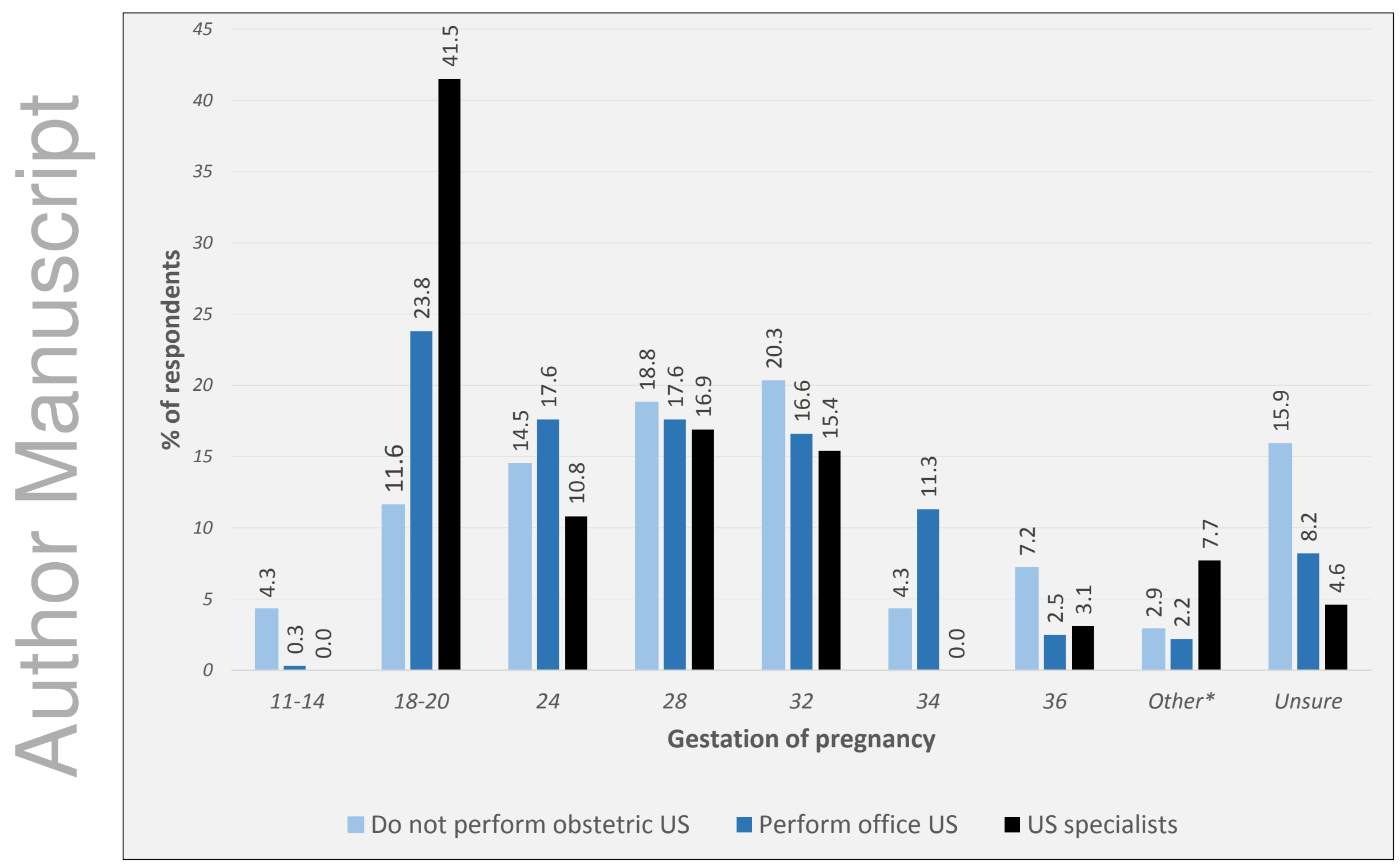

This article is protected by copyright. All rights reserved 


\section{University Library}

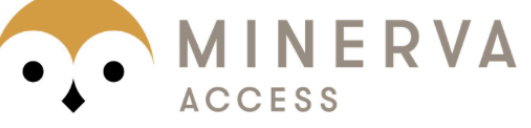

A gateway to Melbourne's research publications

Minerva Access is the Institutional Repository of The University of Melbourne

Author/s:

Javid, N;Hyett, JA;Walker, SP;Sullivan, EA;Homer, CSE

Title:

A survey of opinion and practice regarding prenatal diagnosis of vasa previa among obstetricians from Australia and New Zealand

Date:

2019-03-01

\section{Citation:}

Javid, N., Hyett, J. A., Walker, S. P., Sullivan, E. A. \& Homer, C. S. E. (2019). A survey of opinion and practice regarding prenatal diagnosis of vasa previa among obstetricians from Australia and New Zealand. INTERNATIONAL JOURNAL OF GYNECOLOGY \& OBSTETRICS, 144 (3), pp.252-259. https://doi.org/10.1002/ijgo.12747.

Persistent Link:

http://hdl.handle.net/11343/285290 